\title{
Effect of Control Method on Impedance-Based Interactions in a Buck Converter
}

Sanna Vesti,

\author{
Teuvo Suntio, \\ Roberto Prieto,
}

\author{
Jesús Á. Oliver,
}

\begin{abstract}
All the interconnected regulated systems are prone to impedance-based interactions making them sensitive to instability and transient-performance degradation. The applied control method affects significantly the characteristics of the converter in terms of sensitivity to different impedance interactions. This paper provides for the first time the whole set of impedance-type internal parameters and the formulas according to which the interaction sensitivity can be fully explained and analyzed. The formulation given in this paper can be utilized equally either based on measured frequency responses or on predicted analytic transfer functions. Usually, the distributed dc-dc systems are constructed by using ready-made power modules without having thorough knowledge on the actual power-stage and control-system designs. As a consequence, the interaction characterization has to be based on the frequency responses measureable via the input and output terminals. A buck converter with four different control methods is experimentally characterized in frequency domain to demonstrate the effect of control method on the interaction sensitivity. The presented analytical models are used to explain the phenomena behind the changes in the interaction sensitivity.
\end{abstract}

Index Terms-Buck converter, dynamic behavior, minor-loop gain, source/load interactions, stability.

\section{INTRODUCTION}

I $\mathrm{T}$ is well known since the early 1970 s that the interconnected regulated systems are prone to instability and transient performance degradation due to the different impedance interactions within the system [1]-[20]. Most often, the interactions are caused by the $L C$ resonant circuits within the system such as the output impedance of the input filter connected at the input terminal of a converter (i.e., source interactions) [1]-[14] or the input impedance of the input filter of a downstream converter loading the upstream converter (i.e., load interactions) [15]-[18]. The instability and performance degradation can occur also due to the interactions caused by the capacitors and inductors [19], [20]. The stability problems are not only the property of regulated systems, but certain internal feedforward arrangements such as inputvoltage feedforward (IVFF) [21], [22] or constant-power-type load can make the direct-duty-ratio (DDR) controlled converter prone to instability even at open loop.

The theoretical formulation for the source interactions has been laid down in the mid-1970s when Middlebrook published his famous input-filter-design rules [3], [4] based on the canonical dynamic model of a switched-mode converter [23], and the extra-element theorem [24]. It was later observed in practice that the design rules are applicable as such only to the converters operating in continuous conduction mode (CCM) under directduty-ratio control [6]-[9], [25]. Middlebrook launched also the concept known as minor-loop gain as a part of his design rules by means of which the stability of an input-filter-converter system can be assessed. The impedance-based minor-loop gain has been extensively used also to study the stability of more general interconnected systems after its publication [26]-[29].

Specific impedance or admittance parameters [10], [19], implied by the extra-element theorem [24], exist in a switchedmode converter, characterizing the sensitivity of a converter to the impedance-based source and load interactions. These parameters are implicit, not measurable directly, and they may be dependent on the operation mode, and/or the state of external/internal feedback or feedforward arrangements [19]. Their explicit forms cannot be easily found by applying the extraelement theorem due to their complexity and implicit nature (see, e.g., [10]). Most conveniently, they can be obtained applying circuit theory as explained, e.g., in [19]. The sourceand load-affected transfer-function sets in [19] are incomplete, because the special impedance parameters that characterize the load effect on the converter input dynamics are not provided even though they are vital for understanding the full interaction mechanism.

This paper introduces the full set of impedance/admittance parameters describing the sensitivity of a switched-mode converter to the source and load interactions in a form applicable to any dc-dc converter based on measured frequency responses as well as on analytic models. Their dependence on the operation mode (i.e., continuous or discontinuous), the state of outputside feedback, as well as the state of internal feedback and feedforward arrangements are defined. Based on their explicit forms, the differences in the interaction sensitivity of a buck converter under DDR, IVFF, peak-current mode (PCM), and PCM with output-current feedforward (OCF) control arrangements are explicitly explained. These converters are introduced previously in more detail from the dynamic and design point of view in [13], [16], [17], [21], [25], [30], and [31] including the verification of their analytic models to the experimentally measured frequency responses. The given analytical models are 


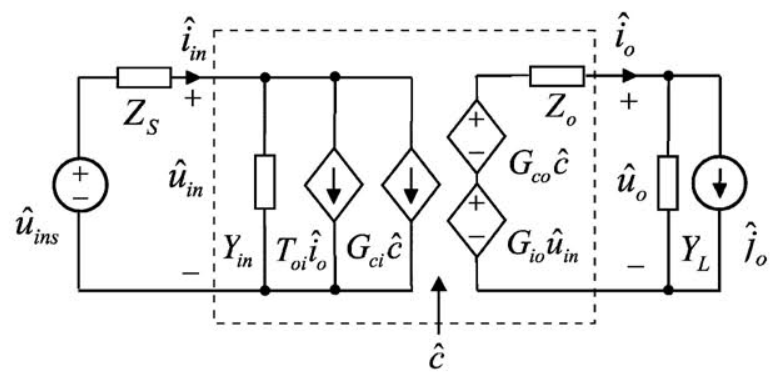

Fig. 1. Two-port linear model of a conventional voltage-fed converter with nonideal source $Z_{S}$ and load $Y_{L}$.

intended to be used to provide explanations for the phenomena demonstrated by means of comprehensive experimental measurements. The comparability of the experiments is ensured by using the same power stage and changing only the control arrangement. The buck-type converter is taken as an example because it is the most frequently utilized building block in the distributed dc-dc systems [32]-[34].

All the measured frequency responses are given as Bode plots although the stability assessment can be performed most conveniently by using Nyquist plots as demonstrated explicitly in [27] and [28]. The stability assessment is not the main focus in this paper and the existence of stability in the converters can be easily determined even from the Bode plots when the corresponding impedances do not overlap each other. It shall be also noted that the Nyquist plot does not apply to assess the other kind of interactions discussed in this paper, where the impedance ratio is a part of the numerator in the interaction formulation.

The rest of this paper is organized as follows. The general source- and load-affected dynamic representations of a conventional voltage-fed converter are introduced and the property of the special impedance/admittance parameters is explained in Section II. The dynamic models of the buck converter with the named control methods and the explicit forms of the special parameters are given and discussed in Section III. The experimental evidence is provided in Section IV, and the conclusions are drawn finally in Section V.

\section{SOURCE- AND LOAD-AFFECTED DyNAMIC REPRESENTATIONS}

The internal or unterminated dynamic representation of a conventional voltage-fed converter can be given by a set of transfer functions according to (1) being equally valid at open and closed loops. The set in (1) can be also represented by the linear two-port model shown in Fig. 1 inside the dashed box. The vectors $\left[\begin{array}{lll}\hat{u}_{\text {in }} & \hat{i}_{\mathrm{o}} & \hat{c}\end{array}\right]^{T}$ and $\left[\begin{array}{ll}\hat{i}_{\text {in }} & \hat{u}_{\mathrm{o}}\end{array}\right]^{T}$ in (1) are the inputvariable and output-variable vectors, respectively, and the input variable $\hat{c}$ denotes the general control variable. The meaning of the different transfer functions can be deduced based on the variables present in the corresponding input and output vectors. The minus sign in front of the output impedance is due to the selected direction of the output current [35]

$$
\left[\begin{array}{c}
\hat{i}_{\text {in }} \\
\hat{u}_{\mathrm{o}}
\end{array}\right]=\left[\begin{array}{ccc}
Y_{\text {in }} & T_{\mathrm{oi}} & G_{\mathrm{ci}} \\
G_{\text {io }} & -Z_{\mathrm{o}} & G_{\mathrm{co}}
\end{array}\right]\left[\begin{array}{c}
\hat{u}_{\text {in }} \\
\hat{i}_{\mathrm{o}} \\
\hat{c}
\end{array}\right] .
$$

The effect of the nonideal source can be found by computing $\hat{u}_{\text {in }}$ from Fig. 1, and substituting it into (1) with the computed formula yielding

$$
\begin{aligned}
{\left[\begin{array}{c}
\hat{i}_{\mathrm{in}} \\
\hat{u}_{\mathrm{o}}
\end{array}\right]=} & {\left[\begin{array}{ccc}
\frac{Y_{\text {in }}}{1+Z_{\mathrm{s}} Y_{\text {in }}} & \frac{T_{\mathrm{oi}}}{1+Z_{\mathrm{S}} Y_{\text {in }}} & \frac{G_{\mathrm{ci}}}{1+Z_{\mathrm{s}} Y_{\text {in }}} \\
\frac{G_{\text {io }}}{1+Z_{\mathrm{s}} Y_{\text {in }}} & -\frac{1+Z_{\mathrm{s}} Y_{\text {in-sco }}}{1+Z_{\mathrm{s}} Y_{\mathrm{in}}} Z_{o} & \frac{1+Z_{\mathrm{s}} Y_{\text {in- } \infty}}{1+Z_{\mathrm{s}} Y_{\text {in }}} G_{\mathrm{co}}
\end{array}\right] } \\
& \times\left[\begin{array}{c}
\hat{u}_{\text {ins }} \\
\hat{i}_{\mathrm{o}} \\
\hat{c}
\end{array}\right]
\end{aligned}
$$

where the ideal input admittance $Y_{\mathrm{in}-\infty}$ and the input impedance at short-circuited output $Y_{\mathrm{in}-\mathrm{sco}}$ are defined in (3) and (4), respectively. Both of these admittances are independent of the state of output-side feedback and the properties of the load but $Y_{\mathrm{in}-\mathrm{sco}}$ in (4) is dependent on the operation mode (i.e., CCM/DCM) and the internal feedback/feedforward arrangements

$$
\begin{gathered}
Y_{\mathrm{in}-\infty}=Y_{\mathrm{in}}-\frac{G_{\mathrm{io}} G_{\mathrm{ci}}}{G_{\mathrm{co}}} \\
Y_{\text {in-sco }}=Y_{\text {in }}+\frac{G_{\mathrm{io}} T_{\mathrm{oi}}}{Z_{\mathrm{o}}} .
\end{gathered}
$$

Correspondingly, the effect of nonideal load can be found by computing $\hat{i}_{\mathrm{o}}$ from Fig. 1, and substituting it into (1) with the computed formula yielding

$$
\begin{aligned}
{\left[\begin{array}{l}
\hat{i}_{\mathrm{in}} \\
\hat{u}_{\mathrm{o}}
\end{array}\right]=} & {\left[\begin{array}{ccc}
\frac{1+Z_{\mathrm{o}-\mathrm{oci}}^{\mathrm{x}} Y_{L}}{1+Z_{\mathrm{o}} Y_{L}} Y_{\mathrm{in}} & \frac{T_{\mathrm{oi}}}{1+Z_{\mathrm{o}} Y_{L}} & \frac{1+Z_{\mathrm{o}-\infty} Y_{L}}{1+Z_{\mathrm{o}} Y_{L}} G_{\mathrm{ci}} \\
\frac{G_{\mathrm{io}}}{1+Z_{\mathrm{o}} Y_{L}} & -\frac{Z_{\mathrm{o}}}{1+Z_{\mathrm{o}} Y_{L}} & \frac{G_{\mathrm{co}}}{1+Z_{\mathrm{o}} Y_{L}}
\end{array}\right] } \\
& \times\left[\begin{array}{c}
\hat{u}_{\mathrm{in}} \\
\hat{j}_{\mathrm{o}} \\
\hat{c}
\end{array}\right]
\end{aligned}
$$

where the ideal output impedance $Z_{\mathrm{o}-\infty}$ and the output impedance at open-circuit input $Z_{\mathrm{o} \text {-oci }}^{\mathrm{x}}$ are defined in (6)-(8), respectively. $Z_{\mathrm{o}-\mathrm{oci}}^{\mathrm{x}}$ is dependent on the state of output-side feedback, and therefore, it has different values at open loop $Z_{\text {o-oci }}^{\circ}$ (7) and closed loop $Z_{\mathrm{o}-\mathrm{oci}}^{\mathrm{c}}(8)$, whereas $Z_{\mathrm{o}-\infty}(6)$ is independent of the state of output-side feedback and the source properties

$$
\begin{aligned}
& Z_{\mathrm{o}-\infty}=Z_{\mathrm{o}}+\frac{G_{\mathrm{co}} T_{\mathrm{oi}}}{G_{\mathrm{ci}}} \\
& Z_{\mathrm{o}-\mathrm{oci}}^{\mathrm{o}}=Z_{\mathrm{o}-\mathrm{o}}+\frac{G_{\mathrm{io-}-\mathrm{o}} T_{\mathrm{oi}-\mathrm{o}}}{Y_{\text {in-o }}}=\frac{Z_{\mathrm{o}-\mathrm{o}}}{Y_{\mathrm{in}-\mathrm{o}}} Y_{\text {in-sco }} \\
& Z_{\mathrm{o}-\mathrm{oci}}^{\mathrm{c}}=Z_{\mathrm{o}-\mathrm{c}}+\frac{G_{\mathrm{io}-\mathrm{c}} T_{\mathrm{oi}-\mathrm{c}}}{Y_{\text {in-c }}}=\frac{Z_{\mathrm{o}-\mathrm{c}}}{Y_{\text {in-c }}} Y_{\text {in-sco }} .
\end{aligned}
$$

The ideal input admittance $Y_{\mathrm{in}-\infty}$ in (3) characterizes the closedloop input admittance of the output-side feedback-controlled converter at the low frequencies, where the corresponding feedback loop gain $L_{\text {out }}$ is high as depicted in (9). Therefore, it is 


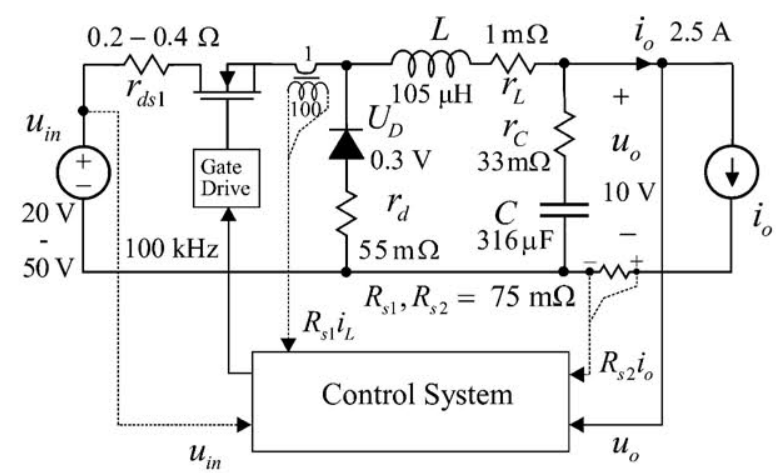

Fig. 2. Experimental buck converter.

also known as an infinite-bandwidth input admittance. Similarly, the ideal output impedance $Z_{0-\infty}$ in (6) characterizes the closed-loop output impedance of the input-side feedbackcontrolled converter at the low frequencies, where the corresponding feedback loop gain $L_{\text {in }}$ is high as depicted in (10). This type of feedback arrangement can be encountered in photovoltaic maximum-power-point tracking converters [36]. The high-gain feedback control changes the input or output terminal to have constant power property, where the ideal parameters represent the ohmic property of the corresponding terminal at low frequencies, i.e., $\left|Y_{\text {in- }-\infty}\right| \approx \frac{I_{\text {in }}}{U_{\text {in }}}$ and $\left|Z_{0-\infty}\right| \approx \frac{U_{o}}{I_{\mathrm{o}}}$

$$
\begin{aligned}
Y_{\text {in-c }} & =\frac{Y_{\text {in-o }}}{1+L_{\text {out }}}+\frac{L_{\text {out }}}{1+L_{\text {out }}} Y_{\text {in }-\infty} \\
Z_{\text {o-c }} & =\frac{Z_{\text {o-o }}}{1+L_{\text {in }}}+\frac{L_{\text {in }}}{1+L_{\text {in }}} Z_{\text {o- } \infty} .
\end{aligned}
$$

\section{DyNAMiC REPRESENTATIONS OF BUCK CONVERTER UNDER DIFFERENT CONTROL METHODS}

The buck-converter power stage with the defined component values is shown in Fig. 2. Detailed methods to model the openloop dynamic behavior of this converter under the different control arrangements can be found, e.g., from [31]. The duty ratio of the buck converter can be solved from (11) when the input and output voltages and the load current are defined. The analytical models given in this paper are valid in CCM. The discontinuous-mode (DCM) models can be found, e.g., from [31].

$$
D=\frac{U_{\mathrm{o}}+U_{\mathrm{D}}+\left(r_{L}+r_{\mathrm{d}}\right) I_{\mathrm{o}}}{U_{\mathrm{in}}+U_{\mathrm{D}}+\left(r_{\mathrm{d}}-r_{\mathrm{ds} 1}\right) I_{\mathrm{o}}} .
$$

\section{A. DDR-Controlled Buck Converter}

The set of open-loop transfer functions of the DDR-controlled buck converter can be given according to (12) applying the statespace averaging method [23], [31]. The validity of the analytic models in (12) is verified, e.g., in [31, pp. 95-107]. The detailed description of the control design and the controller parameters can be found from [31: pp. 285-290]

$$
\begin{aligned}
& {\left[\begin{array}{ccc}
\frac{D^{2} s}{L} & \frac{D\left(1+s r_{C} C\right)}{L C} & \frac{D U_{\mathrm{E}} s}{L} \\
\frac{D\left(1+s r_{C} C\right)}{L C} & -\frac{\left(r_{\mathrm{E}}+s L\right)\left(1+s r_{C} C\right)}{L C} & \frac{U_{\mathrm{E}}\left(1+s r_{C} C\right)}{L C}
\end{array}\right]} \\
& s^{2}+s \frac{r_{\mathrm{E}}+r_{C}}{L}+\frac{1}{L C} \\
& +\left[\begin{array}{ccc}
0 & 0 & I_{\mathrm{o}} \\
0 & 0 & 0
\end{array}\right] \\
& r_{\mathrm{E}}=r_{L}+D r_{\mathrm{ds} 1}+D^{\prime} r_{\mathrm{d}} \\
& U_{\mathrm{E}}=U_{\mathrm{in}}+U_{\mathrm{D}}+\left(r_{\mathrm{d}}-r_{\mathrm{ds} 1}\right) I_{\mathrm{o}} .
\end{aligned}
$$

The special parameters can be solved according to (3), (4), (6)-(8) by means of the open-loop transfer functions in (12) yielding (13)-(17) when all of them are given as impedances. The open-loop $Z_{\mathrm{o} \text {-oci }}^{\mathrm{o}}$ (16) corresponds to the impedance of the output capacitor, whereas the closed-loop $Z_{\mathrm{o}-\mathrm{oci}}^{\mathrm{c}}$ (17) cannot be explicitly given in symbolic form due to its dependence on the state of feedback. The formulations shown in (5) imply that the increase in output capacitance decreases the load effect on the input impedance. The lowest input-side impedance valueespecially at the low frequencies-is $Z_{\text {in-sco }}(14)$, which easily interacts with the input filter affecting the output impedance as discussed, e.g., in [13]

$$
\begin{aligned}
Z_{\mathrm{in}-\infty} & =-\frac{U_{\mathrm{E}}}{D I_{\mathrm{o}}} \approx-\frac{U_{\mathrm{in}}}{I_{\mathrm{in}}} \\
Z_{\mathrm{in}-\mathrm{sco}} & =\frac{r_{\mathrm{E}}+s L}{D^{2}} \\
Z_{\mathrm{o}-\infty} & =\frac{1}{L C} \cdot \frac{\left(s L+\left(D U_{\mathrm{in}} / I_{\mathrm{o}}\right)+r_{L}+r_{\mathrm{d}}\right)\left(1+s r_{C} C\right)}{s^{2}+s \frac{r_{L}+r_{\mathrm{d}}+r_{C}+\left(D U_{\mathrm{in}} / I_{\mathrm{o}}\right)}{L}+\frac{1}{L C}} \\
& \approx \frac{U_{\mathrm{o}}}{I_{\mathrm{o}}}(s=0) \\
Z_{\mathrm{o}-\mathrm{oci}}^{\mathrm{o}} & =\frac{1+s r_{C} C}{s C} \\
Z_{\mathrm{o}-\mathrm{oci}}^{\mathrm{c}} & =\frac{Z_{\mathrm{o}-\mathrm{c}}}{Y_{\mathrm{in}-\mathrm{c}}} Y_{\text {in-sco }}
\end{aligned}
$$

The DDR-controlled buck converter is occasionally utilized as a bus converter in distributed dc-dc systems, operating at open loop with a fixed duty ratio. Its open-loop input impedance (18) can be significantly affected by the load impedance according to (19), where $\left|R_{L}\right|$ represents the ohmic property of the load impedance, which can be the conventional resistance or the negative incremental input resistance of the regulated downstream converter. Therefore, the low-frequency phase of the input impedance may start from $-180^{\circ}$ even at open loop when loaded by another regulated converter. As a consequence, the input filter might cause the converter to become unstable [13]

$$
\begin{aligned}
& Z_{\text {in-o }}=\frac{s^{2} L C+s\left(r_{\mathrm{E}}+r_{C}\right) C+1}{s D^{2} C} \\
& Z_{\text {in-o }}^{L}=\frac{\left|R_{L}\right|}{D^{2}} \cdot \frac{s^{2} L C+s\left(\left(r_{\mathrm{E}}+r_{C}\right) C+\frac{L}{\left|R_{L}\right|}\right)+1}{1+s\left|R_{L}\right| C} .
\end{aligned}
$$




\section{B. IVFF-Controlled Buck Converter}

The IVFF-controlled converter is derived from the corresponding DDR-controlled converter by providing feedforward from the input voltage as explained in detail in [21]. The set of open-loop transfer functions are given in (20), where the dutyratio and input-voltage-feedforward gains are denoted by $F_{\mathrm{m}}^{\mathrm{IF}}$ and $q_{\mathrm{i}}^{\mathrm{IF}}$, respectively. The validity of the analytic models in (20) is demonstrated in [21] including also the explicit information on the applied control system

$$
\begin{gathered}
{\left[\begin{array}{ccc}
\frac{D\left(D-F_{\mathrm{m}}^{\mathrm{IF}} q_{\mathrm{i}}^{\mathrm{IF}} U_{\mathrm{E}}\right) s}{L} & \frac{D\left(1+s r_{C} C\right)}{L C} & \frac{F_{\mathrm{m}}^{\mathrm{IF}} D U_{\mathrm{E}} s}{L} \\
\frac{\left(D-F_{\mathrm{m}}^{\mathrm{IF}} q_{\mathrm{i}}^{\mathrm{IF}} U_{\mathrm{E}}\right)\left(1+s r_{C} C\right)}{L C}-\frac{\left(r_{\mathrm{E}}+s L\right)\left(1+s r_{C} C\right)}{L C} & \frac{F_{\mathrm{m}}^{\mathrm{IF}} U_{\mathrm{E}}\left(1+s r_{C} C\right)}{L C}
\end{array}\right]} \\
s^{2}+s \frac{r_{\mathrm{E}}+r_{C}}{L}+\frac{1}{L C} \\
+\left[\begin{array}{ccc}
-F_{\mathrm{m}}^{\mathrm{IF}} q_{\mathrm{i}}^{\mathrm{IF}} I_{0} & 0 & F_{\mathrm{m}}^{\mathrm{IF}} I_{0} \\
0 & 0 & 0
\end{array}\right]
\end{gathered}
$$

where $F_{\mathrm{m}}^{\mathrm{IF}} \approx \frac{R_{\mathrm{x}} C_{\mathrm{x}}}{T_{\mathrm{x}} U_{\mathrm{in}}}$ and $q_{\mathrm{i}}^{\mathrm{IF}} \approx \frac{D T_{\mathrm{s}}}{R_{\mathrm{x}} C_{\mathrm{x}}}$ as well as $R_{\mathrm{x}}$ and $C_{\mathrm{x}}$ are the PWM modulator time-base components.

The special parameters can be solved according to (3), (4) and (6)-(8) by means of the presented open-loop transfer functions in (20) yielding (21)-(24) when all of them are given as impedances. The IVFF control is basically designed in such a way that the audiosusceptibility is nullified [21], i.e., $D-F_{\mathrm{m}}^{\mathrm{IF}} q_{\mathrm{i}}^{\mathrm{IF}} U_{\mathrm{E}} \approx 0$. As a consequence, the input-side impedances [ $Z_{\text {in-o }}(20), Z_{\text {in-c }}(9), Z_{\text {in-sco }}(22)$, and $\left.Z_{\text {in- }-\infty}(21)\right]$ are the same equaling $-\left(U_{\mathrm{E}} / D I_{\mathrm{o}}\right)$. In addition, the open-loop $Z_{\mathrm{o}-\mathrm{oci}}^{\mathrm{o}}(24)$ equals the open-loop output impedance $Z_{\mathrm{o}-\mathrm{o}}$, and the closed-loop $Z_{0 \text {-oci }}^{\mathrm{c}}(25)$ equals the closed-loop output impedance

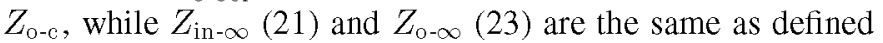
for the DDR-controlled converter in (13) and (15), respectively.

The design of the feedforward gains in such a way that the audiosusceptibility is perfectly nullified is not possible. Therefore, $Z_{\text {in-sco }}$ (22) may not equal the other input impedances perfectly due to the low value of the output impedance especially at low frequencies [see (4)]. Based on (14) and (22), it can be stated that $Z_{\mathrm{in}-\mathrm{sco}}^{\mathrm{IF}}>Z_{\mathrm{in}-\mathrm{sco}}^{\mathrm{DP}}$ yielding reduced interactions compared to the DDR-controlled converter

$$
\begin{aligned}
Z_{\mathrm{in}-\infty} & =-\frac{U_{\mathrm{E}}}{D I_{\mathrm{o}}} \\
Z_{\mathrm{in}-\mathrm{sco}} & =\frac{r_{\mathrm{E}}+s L}{D\left(D-F_{\mathrm{m}}^{\mathrm{IF}} q_{\mathrm{i}}^{\mathrm{IF}} U_{\mathrm{E}}\right)-F_{\mathrm{m}}^{\mathrm{IF}} q_{\mathrm{i}}^{\mathrm{IF}} I_{\mathrm{o}}\left(r_{\mathrm{E}}+s L\right)} \\
Z_{\mathrm{o}-\infty} & =\frac{1}{L C} \cdot \frac{\left(s L+\left(D U_{\mathrm{in}} / I_{\mathrm{o}}\right)+r_{L}+r_{\mathrm{d}}\right)\left(1+s r_{C} C\right)}{s^{2}+s \frac{r_{L}+r_{\mathrm{d}}+r_{C}+\left(D U_{\mathrm{in}} / I_{\mathrm{o}}\right)}{L}+\frac{1}{L C}}
\end{aligned}
$$

$$
\begin{aligned}
& Z_{\mathrm{o}-\mathrm{oci}}^{\mathrm{o}}=\frac{Z_{\mathrm{o}-\mathrm{o}}}{Y_{\mathrm{in}-\mathrm{o}}} Y_{\mathrm{in}-\mathrm{sco}} \\
& Z_{\mathrm{o}-\mathrm{oci}}^{\mathrm{c}}=\frac{Z_{\mathrm{o}-\mathrm{c}}}{Y_{\mathrm{in}-\mathrm{c}}} Y_{\mathrm{in}-\mathrm{sco}} .
\end{aligned}
$$

An IVFF-controlled buck converter is occasionally used as a bus converter in dc-dc distributed systems due to its ability to maintain the output voltage at acceptable level without outputvoltage feedback despite the changes in input voltage [22]. However, the negative-incremental-resistance property of the converter input terminal makes it prone to instability due to the input-filter interactions even at open loop.

\section{PCM-Controlled Buck Converter}

The detailed methods to model the dynamics of the PCMcontrolled converter can be found, e.g., from [31] according to which the set of open-loop transfer function can be given as in (26) shown at the bottom of the page, where the duty-ratio gain $F_{\mathrm{m}}^{\mathrm{PC}}$, the inductor-current feedback gain $q_{\mathrm{c}}^{\mathrm{PC}}$, and the IVFF gain $q_{\mathrm{i}}^{\mathrm{PC}}$ are defined in (27)-(29), respectively. The accuracy of the analytic models in (26) is validated in [31, pp. 146-157]. The detailed description of the control design and the controller parameters can be found from [31, pp. 290-295]

$$
\begin{aligned}
F_{\mathrm{m}}^{\mathrm{PC}} & =\frac{1}{T_{\mathrm{s}}\left(M_{\mathrm{c}}+\frac{\left(D^{\prime}-D\right) U_{\mathrm{E}}}{2 L}\right)} \\
q_{\mathrm{c}}^{\mathrm{PC}} & =1+\frac{D D^{\prime} T_{\mathrm{s}}}{2 L}\left(r_{\mathrm{d}}-r_{\mathrm{ds} 1}\right) \\
q_{\mathrm{i}}^{\mathrm{PC}} & =\frac{D D^{\prime} T_{\mathrm{s}}}{2 L} .
\end{aligned}
$$

The special parameters can be solved according to (3), (4), (6)-(8) by means of the open-loop transfer functions in (26) yielding (30)-(34) when all of them are given as impedances. The inductor-current-loop compensation $\left(M_{\mathrm{c}}=D U_{\mathrm{E}} / 2 L\right)$ is usually designed in such a way that the audiosusceptibility is nullified [30], i.e., $D-F_{\mathrm{m}}^{\mathrm{PC}} q_{\mathrm{i}}^{\mathrm{PC}} U_{\mathrm{E}} \approx 0$. Consequently, all the input-side impedances $\left(Z_{\text {in-o }}(20), Z_{\text {in-c }}(9), Z_{\text {in-sco }}(31)\right.$,

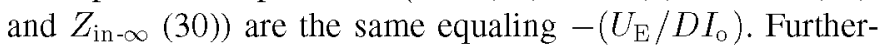
more, the open-loop $Z_{\text {o-oci }}^{\circ}$ (33) equals the open-loop output impedance $Z_{\mathrm{o}-\mathrm{o}}(20)$, and the closed-loop $Z_{\mathrm{o}-\mathrm{oci}}^{\mathrm{c}}(34)$ equals the closed-loop output impedance $Z_{0-0}(9)$, respectively, while

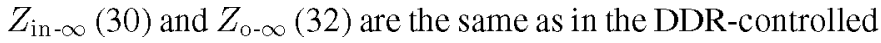
converter in (13) and (15).

The design of the inductor-current-loop compensation in such a way that the audiosusceptibility is perfectly nullified is not possible. This imperfectness does not affect $Z_{\text {in-sco }}^{\text {PC }}$ (31) similarly as $Z_{\mathrm{in}-\mathrm{sco}}^{\mathrm{IF}}(22)$, because the open-loop output impedance of the

$$
\begin{aligned}
& \frac{\left[\begin{array}{ccc}
\frac{\left(D-F_{\mathrm{m}}^{\mathrm{PC}} q_{\mathrm{j}}^{\mathrm{PC}} U_{\mathrm{E}}\right)\left(D-F_{\mathrm{m}}^{\mathrm{PC}} q_{\mathrm{c}}^{\mathrm{PC}} I_{\mathrm{o}}\right) s}{L} & \frac{\left(D-F_{\mathrm{m}}^{\mathrm{PC}} q_{\mathrm{c}}^{\mathrm{PC}} I_{0}\right)\left(1+s r_{C} C\right)}{L C} & \frac{F_{\mathrm{m}}^{\mathrm{PC}} U_{\mathrm{E}}\left(D-F_{\mathrm{m}}^{\mathrm{PC}} q_{\mathrm{c}}^{\mathrm{PC}} I_{0}\right) s}{L} \\
\frac{\left(D-F_{\mathrm{m}}^{\mathrm{PC}} q_{\mathrm{j}}^{\mathrm{PC}} U_{\mathrm{E}}\right)\left(1+s r_{C} C\right)}{L C} & -\frac{\left(r_{\mathrm{E}}+F_{\mathrm{m}}^{\mathrm{PC}} q_{\mathrm{c}}^{\mathrm{PC}} U_{\mathrm{E}}+s L\right)\left(1+s r_{C} C\right)}{L C} & \frac{F_{\mathrm{m}}^{\mathrm{PC}} U_{\mathrm{E}}\left(1+s r_{C} C\right)}{L C}
\end{array}\right]}{s^{2}+s \cdot \frac{r_{\mathrm{E}}+F_{\mathrm{m}}^{\mathrm{PC} C} q_{\mathrm{c}}^{\mathrm{PC}} U_{\mathrm{E}}+r_{C}}{L}+\frac{1}{L C}} \\
& +\left[\begin{array}{ccc}
-F_{\mathrm{m}}^{\mathrm{PC}} q_{\mathrm{i}}^{\mathrm{PC}} I_{0} & 0 & F_{\mathrm{m}}^{\mathrm{PC}} I_{0} \\
0 & 0 & 0
\end{array}\right]
\end{aligned}
$$


PCM-controlled converter is large at the low frequencies [see (4)]

$$
\begin{aligned}
& Z_{\text {in }-\infty}=-\frac{U_{\mathrm{E}}}{D I_{\mathrm{o}}} \\
& Z_{\mathrm{in}-\mathrm{sco}}= \\
& \frac{r_{\mathrm{E}}+F_{\mathrm{m}}^{\mathrm{PC}} q_{\mathrm{c}}^{\mathrm{PC}} U_{\mathrm{E}}+s L}{D\left(D-F_{\mathrm{m}}^{\mathrm{PC}} q_{\mathrm{i}}^{\mathrm{PC}} U_{\mathrm{E}}\right)-F_{\mathrm{m}}^{\mathrm{PC}} q_{\mathrm{i}}^{\mathrm{PC}} I_{\mathrm{o}}\left(r_{\mathrm{E}}+F_{\mathrm{m}}^{\mathrm{PC}} q_{\mathrm{c}}^{\mathrm{PC}}+s L F\right)} \\
& Z_{\mathrm{o}-\infty}=\frac{1}{L C} \cdot \frac{\left(s L+\left(D U_{\mathrm{in}} / I_{\mathrm{o}}\right)+r_{L}+r_{\mathrm{d}}\right)\left(1+s r_{C} C\right)}{s^{2}+s \frac{r_{L}+r_{\mathrm{d}}+r_{\mathrm{C}}+\left(D U_{\mathrm{in}} / I_{\mathrm{o}}\right)}{L}+\frac{1}{L C}} \\
& Z_{\mathrm{o}-\mathrm{oci}}^{\circ}=\frac{Z_{\mathrm{o}-\mathrm{o}}}{Y_{\text {in-o }}} Y_{\text {in-sco }} \\
& Z_{\mathrm{o}-\mathrm{oci}}^{\mathrm{c}}=\frac{Z_{\mathrm{o}-\mathrm{c}}}{Y_{\text {in-co }}} Y_{\text {in-sco }} .
\end{aligned}
$$

\section{PCM-OCF-Controlled Buck Converter}

The dynamic models for the PCM-OCF-controlled converter can be derived based on the PCM-controlled converter models as instructed in detail in [30]. When the gain of the outputcurrent-feedforward loop is taken as unity and the equivalent current-sensing resistor $\left(R_{\mathrm{si}}\right)$ are equal, the set of open-loop transfer functions can be given by (35). The accuracy of the analytic models in (35) as shown at the bottom of the page, is validated in [30]. The detailed description of the control design and the controller parameters can be found from [30].

The special parameters can be solved according to (3), (4), (6)-(8) by means of the open-loop transfer functions in (35) yielding (36)-(40) when all of them are given as impedances. The inductor-current-loop compensation $\left(M_{\mathrm{c}}=D U_{\mathrm{E}} / 2 L\right)$ is usually designed in such a way that the audiosusceptibility is nullified [30], i.e., $D-F_{\mathrm{m}}^{\mathrm{PC}} q_{\mathrm{i}}^{\mathrm{PC}} U_{\mathrm{E}} \approx 0$. As a consequence, all the input-side impedances $\left[Z_{\text {in-o }}(35), Z_{\text {in-c }}(9), Z_{\text {in-sco }}(37)\right.$, and

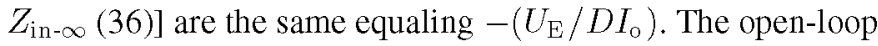
$Z_{\text {o-oci }}^{\circ}$ (39) equals the open-loop output impedance $Z_{0-\text { o }}$ (35), and the closed-loop $Z_{0-\text { oci }}^{\mathrm{c}}$ (40) equals the closed-loop output impedance $Z_{0-\mathrm{c}}(9) . Z_{\mathrm{in}-\infty}$ (36) and $Z_{\mathrm{o}-\infty}$ (38) are the same as in the DDR-controlled converter in (13) and (15).

The perfect nullification of the audiosusceptibility is difficult to obtain in practice as discussed previously. Therefore, $Z_{\text {in-sco }}^{\mathrm{PC}-\mathrm{OCF}}(31)$ may not equal the other input impedances as in the case of the PCM-controlled converter, because the open-loop output impedance (35) is small by design [see (4)]. This means that the PCM-OCF-controlled converter may be more sensitive to source effects than the pure PCM-controlled converter

$$
\begin{aligned}
Z_{\text {in- }-\infty} & =-\frac{U_{\mathrm{E}}}{D I_{\mathrm{o}}} \\
Z_{\mathrm{in}-\mathrm{sco}} & =\frac{r_{\mathrm{E}}+s L}{D\left(D-F_{\mathrm{m}}^{\mathrm{PC}} q_{\mathrm{i}}^{\mathrm{PC}} U_{\mathrm{E}}\right)-F_{\mathrm{m}}^{\mathrm{PC}} q_{\mathrm{i}}^{\mathrm{PC}} I_{\mathrm{o}}\left(r_{\mathrm{E}}+s L\right)} \\
Z_{\mathrm{o}-\infty} & =\frac{1}{L C} \cdot \frac{\left(s L+\left(D U_{\mathrm{in}} / I_{\mathrm{o}}\right)+r_{L}+r_{\mathrm{d}}\right)\left(1+s r_{C} C\right)}{s^{2}+s \frac{r_{L}+r_{\mathrm{d}}+r_{C}+\left(D U_{\mathrm{in}} / I_{\mathrm{o}}\right)}{L}+\frac{1}{L C}} \\
Z_{\mathrm{o}-\mathrm{oci}}^{\mathrm{o}} & =\frac{Z_{\mathrm{o}-\mathrm{o}}}{Y_{\mathrm{in}-\mathrm{o}}} Y_{\text {in-sco }} \\
Z_{\mathrm{o}-\mathrm{oci}}^{\mathrm{c}} & =\frac{Z_{\mathrm{o}-\mathrm{c}}}{Y_{\text {in-c }}} Y_{\text {in-sco }} .
\end{aligned}
$$

\section{E. Theoretical Discussions}

The main interaction formulations are collected in (41)-(44), where the superscripts " $S$ " and " $L$ " denote load and sourceaffected transfer functions, respectively. The source- and loadside minor-loop gains are $Z_{\mathrm{S}} Y_{\text {in }}$ and $Z_{0} Y_{L}$, respectively. The source-induced instability typically occurs, when the source impedance exceeds the ideal input impedance $Z_{\text {in- } \infty}$ of the converter, which is well known already from the early 1970s [1]. The reasons for the load-imposed instability are more complicated (see, e.g., [16]). The minor-loop gains form an impedance-based sensitivity function [i.e., $1 /(1+Z Y)$ ], which causes peaking if the gain and/or phase margins of the minor-loop gain are small affecting the corresponding source or load-affected transfer function in (41)-(44) (see, e.g., [19] and [27])

$$
\begin{aligned}
L_{\mathrm{out}}^{S} & =\frac{1+Z_{\mathrm{s}} Y_{\text {in }-\infty}}{1+Z_{\mathrm{s}} Y_{\text {in-o }}} L_{\text {out }} \\
Z_{\mathrm{o}}^{S} & =\frac{1+Z_{\mathrm{s}} Y_{\text {in }-\mathrm{sco}}}{1+Z_{\mathrm{s}} Y_{\mathrm{in}}} Z_{\mathrm{o}} \\
L_{\mathrm{out}}^{L} & =\frac{L_{\text {out }}}{1+Z_{\mathrm{o}-\mathrm{o}} Y_{L}} \\
L_{\mathrm{in}}^{L} & =\frac{1+Z_{\mathrm{o}-\mathrm{oci}}^{\mathrm{x}} Y_{L}}{1+Z_{\mathrm{o}} Y_{L}} Y_{\mathrm{in}} .
\end{aligned}
$$

The high input-noise attenuation (i.e., $\left.G_{\mathrm{io-}-\mathrm{o}} \ll 1(1)\right)$ in IVFF-, PCM-, and PCM-OCF-controlled buck converter makes all the input-side impedances as well as the relevant output-side impedances to equal each other. As a consequence, the interaction propagation between the input and output terminals is prevented. In (41)-(44), this means that the numerator and denominator polynomials are the same, thus canceling each other. This phenomenon explains the observed lack of input-filter interactions in [6] and [7]. The DDR control in a buck converter

$$
\begin{gathered}
\frac{\left[\begin{array}{ccc}
\frac{\left(D-F_{\mathrm{m}}^{\mathrm{PC}} q_{\mathrm{j}}^{\mathrm{PC}} U_{\mathrm{E}}\right)\left(D-F_{\mathrm{m}}^{\mathrm{PC}} I_{\mathrm{o}}\right) s}{L} & \frac{\left(D-F_{\mathrm{m}}^{\mathrm{PC}} I_{\mathrm{o}}\right)\left(1+s\left(r_{C}+F_{\mathrm{m}}^{\mathrm{PC}} U_{\mathrm{E}}\right) C\right)}{L C} & \frac{F_{\mathrm{m}}^{\mathrm{PC}} U_{\mathrm{E}}\left(D-F_{\mathrm{m}}^{\mathrm{PC}} I_{\circ}\right) s}{R_{s 1} L} \\
\frac{\left(D-F_{\mathrm{m}}^{\mathrm{PC}} q_{\mathrm{j}}^{\mathrm{PC}} U_{\mathrm{E}}\right)\left(1+s r_{C} C\right)}{L C} & -\frac{\left(r_{\mathrm{E}}+s L\right)\left(1+s r_{C} C\right)}{L C} & \frac{F_{\mathrm{m}}^{\mathrm{PC}} U_{\mathrm{E}}\left(1+s r_{\circ} C\right)}{R_{\mathrm{s}} L C}
\end{array}\right]}{\Delta=s^{2}+s \cdot \frac{r_{\mathrm{E}}+F_{\mathrm{m}}^{\mathrm{PC}} U_{\mathrm{E}}+r_{C}}{L}+\frac{1}{L C}} \\
\quad+\left[\begin{array}{ccc}
-F_{\mathrm{m}}^{\mathrm{PC}} q_{\mathrm{i}}^{\mathrm{PC}} I_{\mathrm{o}} & F_{\mathrm{m}}^{\mathrm{PC}} I_{\mathrm{o}} & \frac{F_{\mathrm{m}}^{\mathrm{PC}} I_{\mathrm{o}}}{R_{\mathrm{s}} 1} \\
0 & 0 & 0
\end{array}\right]
\end{gathered}
$$


does not produce similar property, and therefore, the DDRcontrolled buck converter is very sensitive to source and load interactions.

The output-voltage-loop-gain sensitivity to the load impedance is determined by the shape of the magnitude of the open-loop output impedance. In the DDR- and IVFF-controlled buck converters, the open-loop output impedances are the same if the power stages are identical [see (12) and (20)]. This output impedance has low magnitude at low frequencies and resonant peaking at the converter resonant frequency. As a consequence, the output-voltage loop gain is most sensitive to the load interactions in the vicinity of the resonant frequency, where the output impedance has the highest value. The low-frequency magnitude of the PCM-controlled converter output impedance is known to be high due to its current-output nature [see (26)]. Therefore, the output-voltage loop gain is most sensitive to the load interactions at the low frequencies. The open-loop output impedance of the PCM-OCF-controlled converter is small [see (35)] due to the lack of resonant behavior. Thus, the output-voltage loop gain of the PCM-OCF-controlled converter is extremely insensitive to the load interactions.

\section{EXPERIMENTAL EVIDENCE}

The experimental frequency-response (FR) measurements were performed by using Venable Industries' FR analyzer Model 3120 with an impedance measurement kit. The buck power stage is given in Fig. 2. A single-stage $L C$ filter is connected at the converter input terminal composing of a $500-\mu \mathrm{H}$ inductor with an equivalent series resistance (ESR) of $0.2 \Omega$, and a $200-\mu \mathrm{F}$ capacitor with an ESR of $45 \mathrm{~m} \Omega$. The series $L C$ circuit connected at the converter output terminal composes of a $230-\mu \mathrm{H}$ inductor with an ESR of $0.1 \Omega$, and a $440-\mu \mathrm{F}$ capacitor with an ESR of $10 \mathrm{~m} \Omega$. The output-voltage loop gains are designed to be close to each other at the input voltage of $50 \mathrm{~V}$ having the crossover frequency approximately at $10 \mathrm{kHz}$. The measurements are performed under the operating condition, where the converter input impedance is the lowest, i.e., at the input voltage of $20 \mathrm{~V}$ and full output power of $25 \mathrm{~W}$, thus maximizing the input-side interactions. The measured output-voltage loop gains are presented in Fig. 3 showing that the voltage-loop crossover frequency of the DDR-controlled converter has reduced by $4 \mathrm{kHz}$ from the nominal condition due to the reduction in input voltage. The loop gains of the PCM- and IVFF-controlled converter are not affected by the reduction in input voltage, which is the characteristic property of PCM and IVFF controls. The original outputvoltage responses of the buck converter under different control methods at the input voltage of $20 \mathrm{~V}$ are given in Fig. 4. The behavior of the output-voltage responses reflects the behavior of the closed-loop output impedances given in the subsequent sections as explained in detail in [31, pp. 266-268].

Fig. 5 shows the measured closed-loop input impedances of the buck converter under different control methods including the output impedance of the input filter. The resonant frequency of the input $L C$ filter $(500 \mathrm{~Hz})$ was intentionally chosen to be close to the resonant frequency of the converter $(900 \mathrm{~Hz})$. Fig. 4 shows that the converters are stable (i.e., $Z_{\mathrm{s}}<Z_{\text {in-c }}$ ). The behavior
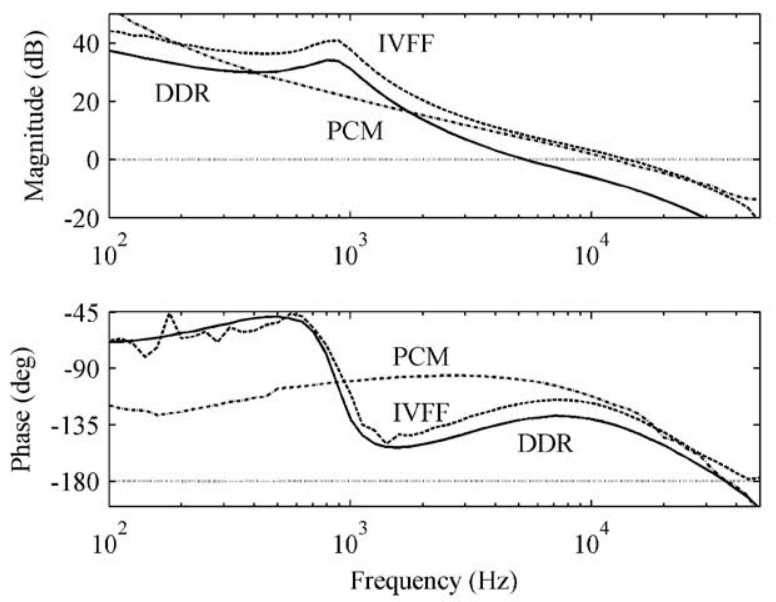

Fig. 3. Measured frequency responses of the output-voltage loop gains at the input voltage of $20 \mathrm{~V}$ (DDR: solid line, IVFF: dotted line, PCM: dash-dotted line).

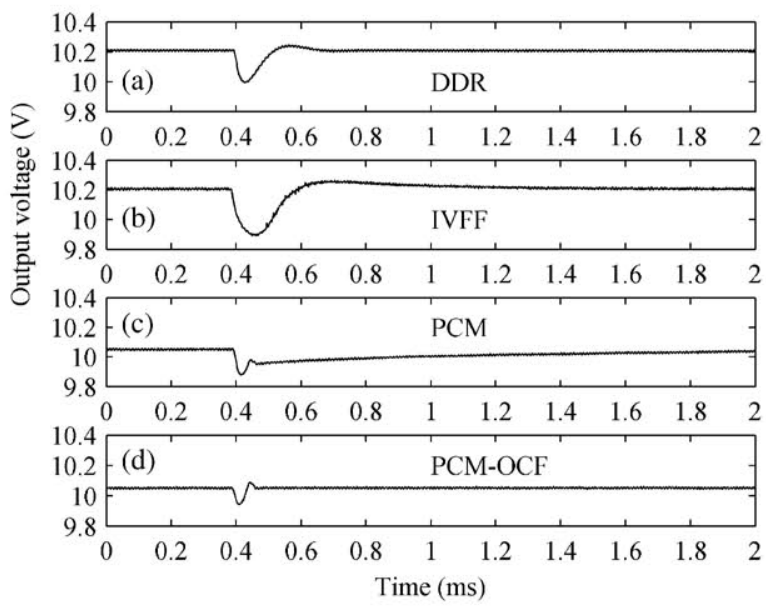

Fig. 4. Measured output-voltage responses to the constant-current-type load change from 0.2 to $2.5 \mathrm{~A}(250 \mathrm{~mA} / \mu \mathrm{s})$ of the buck converter under (a) DDR, (b) IVFF, (c) PCM, and (d) PCM-OCF control.
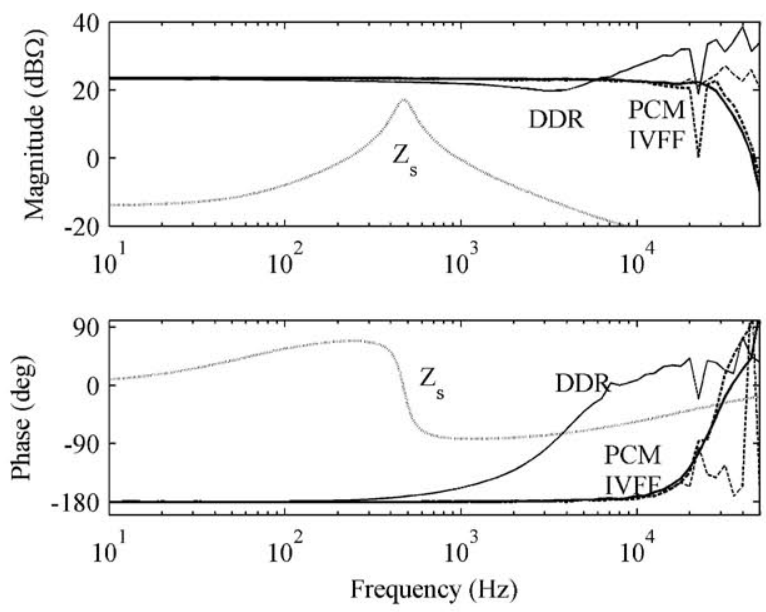

Fig. 5. Measured closed-loop input impedances and the output impedance of the $L C$ filter. 

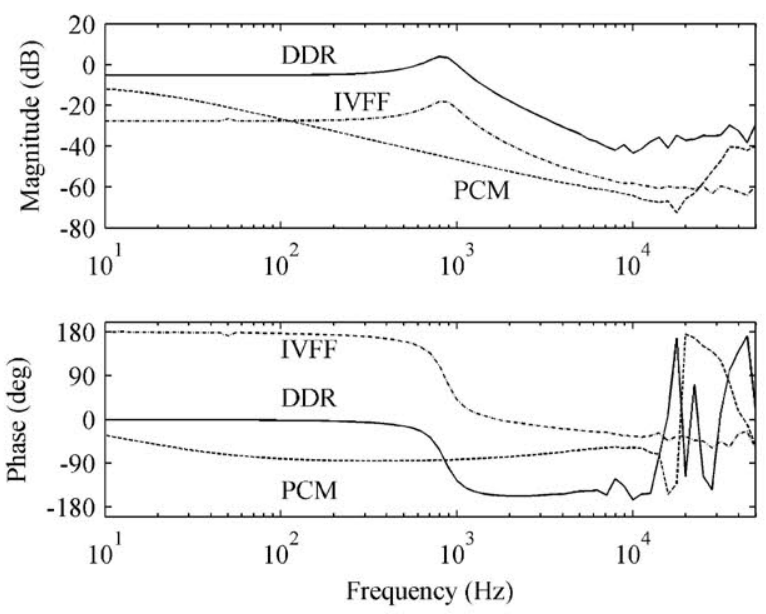

Fig. 6. Measured open-loop audiosusceptibilities at the input voltage of $20 \mathrm{~V}$.
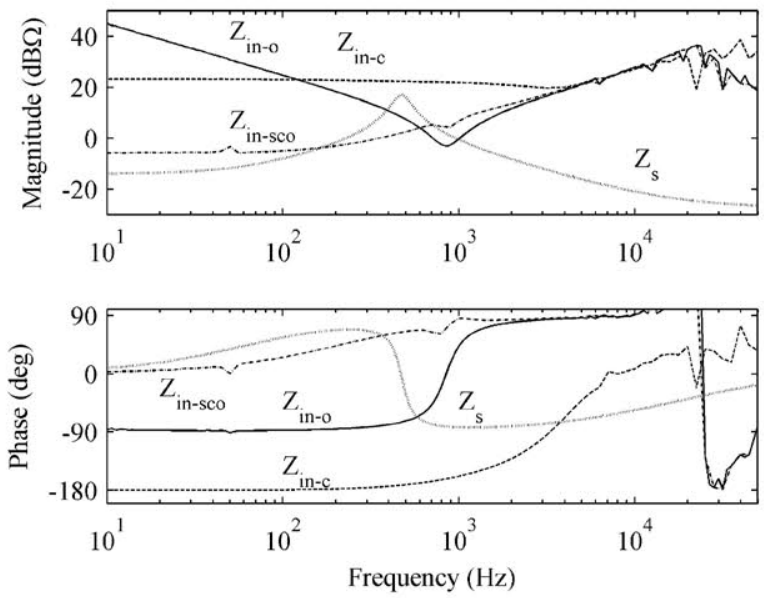

Fig. 7. Measured input-side impedances of the DDR-controlled buck converter with the output impedance of the input filter.

of the phase of the input impedance of the DDR-controlled converter differs significantly from the phase behavior of the other converters as discussed earlier.

The measured open-loop audiosusceptibilities are illustrated in Fig. 6. The figure shows that the IVFF-controlled converter has the highest input-noise attenuation at low frequencies but the resonant behavior causes reduction in the attenuation in the vicinity of the resonant frequency. The figure shows also that the input attenuation of the DDR-controlled converter is the worst at the resonant frequency.

\section{A. DDR-Controlled Buck Converter}

The measured open-loop $Z_{\text {in-o }}$, closed-loop $Z_{\text {in-c }}$, and shortcircuit $Z_{\text {in-sco }}$ input impedances of the DDR-controlled converter with the input-filter output impedance are shown in Fig. 7. It can be observed that the filter output impedance intersects with the open- and short-circuit input impedances, which means that the output-voltage loop gain and the output impedance would be affected. The peak of the input-filter output impedance is relatively close to the magnitude of the converter closed-loop input impedance, which implies peaking in the impedance-based sen-
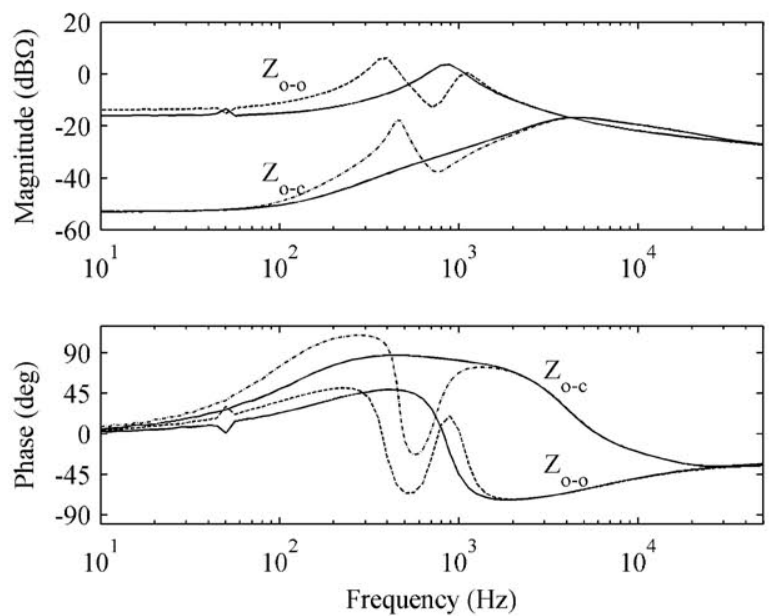

Fig. 8. Measured output impedances of the DDR-controlled converter (solid lines: the unaffected impedances, dashed lines: the source-affected impedances).

sitivity function affecting the closed-loop output impedance. The corresponding source-affected loop gain is shown in [17] validating the implication extractable from Fig. 7 (i.e., $Z_{\text {in-o }}$ intersects with $Z_{s}$ ).

Fig. 8 shows the measured unaffected (solid line) and sourceaffected (dashed line) output impedances: the peaking in the open-loop output impedance is caused by the filter output and the converter short-circuit input impedance intersection, whereas the dipping is caused by the filter output and the converter open-loop input impedance intersection. The closed-loop output impedance peaking is caused by the intersection of the filter output and the converter short-circuit input impedance as well as the peaking in the impedance-based sensitivity function. It can be observed that the peaking in the closed-loop input impedance is clearly higher than in the open-loop output impedance. The behavior of the output impedances also demonstrates that the short-circuit impedance is not dependent on the state of feedback as previously discussed. Figs. 7 and 8 clearly show that the short-circuit input impedance is the usual source of inputfilter interactions affecting the load-transient performance as discussed in [13].

Fig. 9 shows all the measured DDR-controlled-converter output impedances (i.e., $Z_{\mathrm{o}-\mathrm{o}}, Z_{\mathrm{o}-\mathrm{c}}, Z_{\mathrm{o}-\infty}, Z_{\mathrm{o}-\mathrm{oci}}^{\mathrm{o}}$, and $Z_{\mathrm{o}-\mathrm{oci}}^{\mathrm{c}}$ ) as well as the input impedance $\left(Z_{L}\right)$ of the series resonant circuit connected at the converter output terminal. The open-loop $Z_{\mathrm{o} \text { oc }}^{\mathrm{o}}$ is clearly the impedance of the output capacitor as predicted in (16). At the low frequencies, $Z_{0-\infty}$ has the property of resistance depicting the constant-power nature of the input-currentcontrolled converter as discussed in Section II. The closed-loop $Z_{\mathrm{o}-\mathrm{oci}}^{\mathrm{c}}$ is higher than the closed-loop output impedance $Z_{\mathrm{o-c}}$ determining the stability behavior of the converter in the case of the load interactions. Furthermore, the load impedance $Z_{L}$ intersects with the open-loop, ideal, and open-circuit output impedances, implying that the output-voltage loop gain as well as the open- and closed-loop input impedances are affected. The level of the affection in the output-voltage loop gain can be found from [17]. Fig. 10 shows that the open- and closed-loop input impedances are affected by the resonant load as a comparison to 

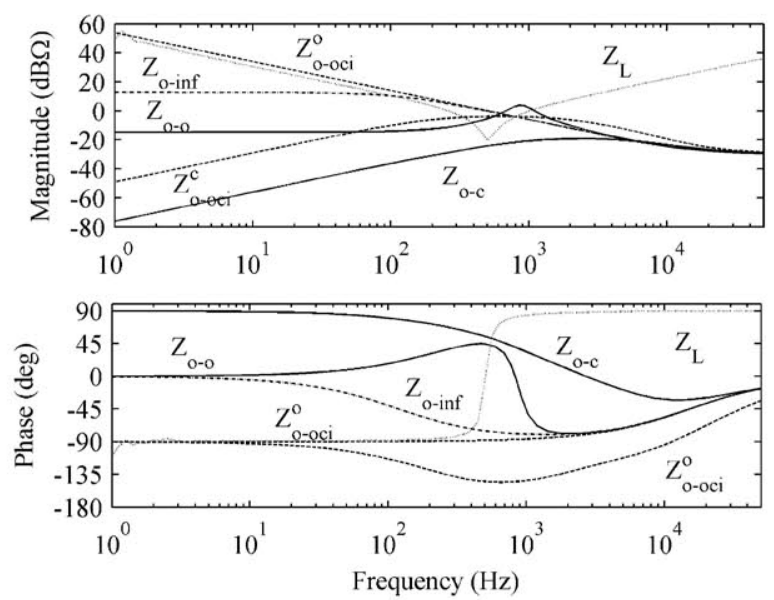

Fig. 9. Output impedances of the DDR-controlled converter and the input impedance of the series-resonant $L C$ circuit connected at the output terminal.
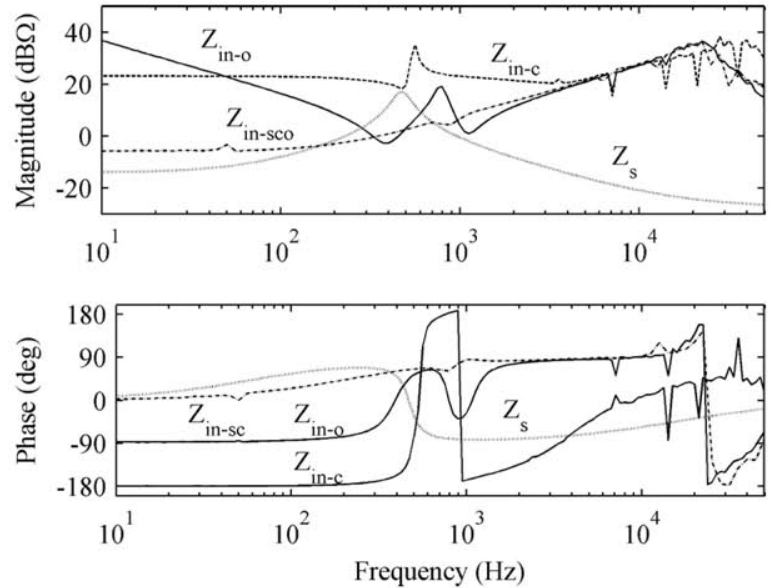

Fig. 10. Measured load-affected input impedances of the DDR-controlled converter with the input-filter output impedance.

Fig. 7. The magnitude and phase behaviors of the closed-loop input impedance $Z_{\text {in-c }}$ and the filter output impedance $Z_{\mathrm{s}}$ indicate that the converter is close to instability due to the simultaneous source and load interactions as will be demonstrated later.

Fig. 11 shows the output-voltage responses of the DDRcontrolled converter to the constant-current-type load change at different combinations of the input and load-side $L C$-type impedances. The initial dip in the output-voltage responses is clearly not changed despite the changes in the output impedance compared to the original response in Fig. 11(a). The resonant behavior of the closed-loop output impedance in Fig. 8 within the control bandwidth affects the settling behavior [see responses in Fig. 11(b) and (c)]. The responses in Fig. 11(c) and (d) show that the time-domain responses do not provide information on the robust stability of the converter, because the only difference between them is the lightly prolonged decaying of oscillation although there are significant differences in the robustness of stability as shown explicitly in Fig. 12.

The minor-loop gains measured at the input $M_{L C}^{S}$ and output $M_{L C}^{L}$ of the converter are presented in Fig. 12(a) as Bode plots and in Fig. 12(b) as Nyquist plots, where the subscript " $L C$ "

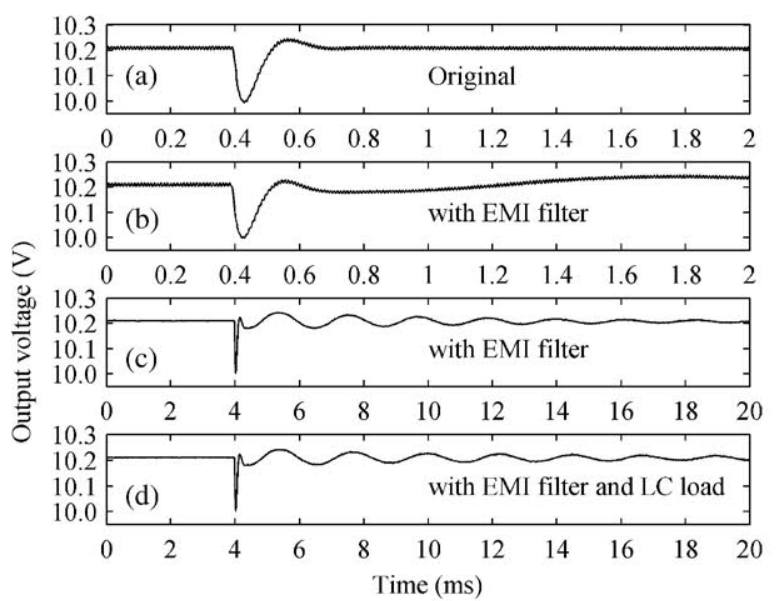

Fig. 11. Measured output-voltage responses to the constant-current-type load change from 0.2 to $2.5 \mathrm{~A}(250 \mathrm{~mA} / \mu \mathrm{s})$ as the consequence of source and load interactions.
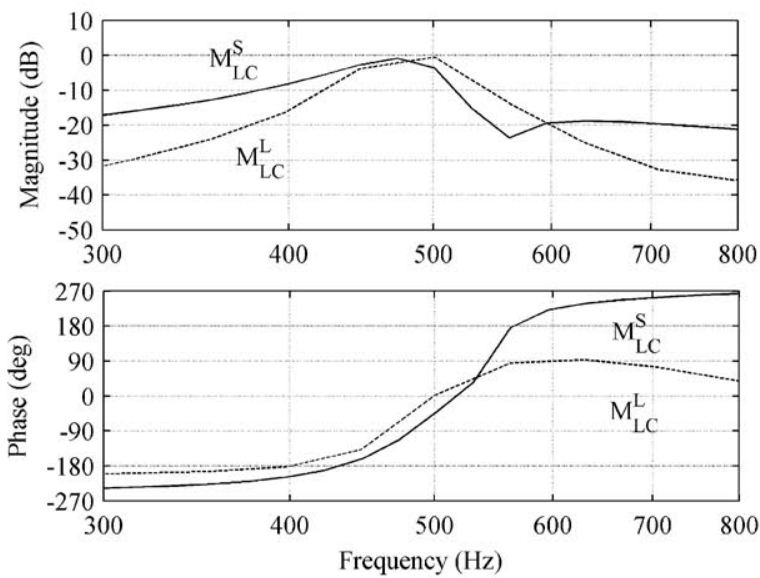

(a)

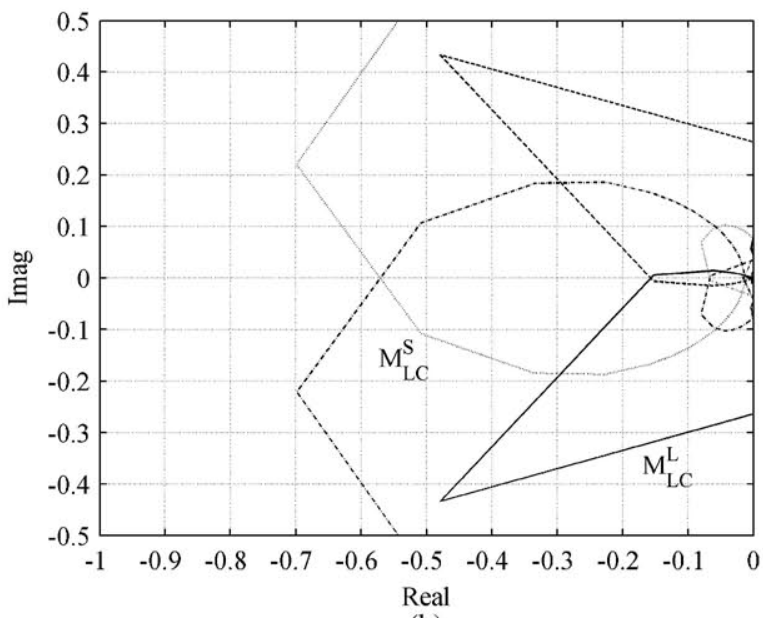

(b)

Fig. 12. Measured source- and load-affected minor-loop gains at the input side $\left(M_{L C}^{S}\right.$, solid line) and output side $\left(M_{L C}^{L}\right.$, dashed line) as (a) Bode plots and (b) Nyquist plots, where the subscript " $L C$ " means that both the resonant circuits affect the converter at the same time. 

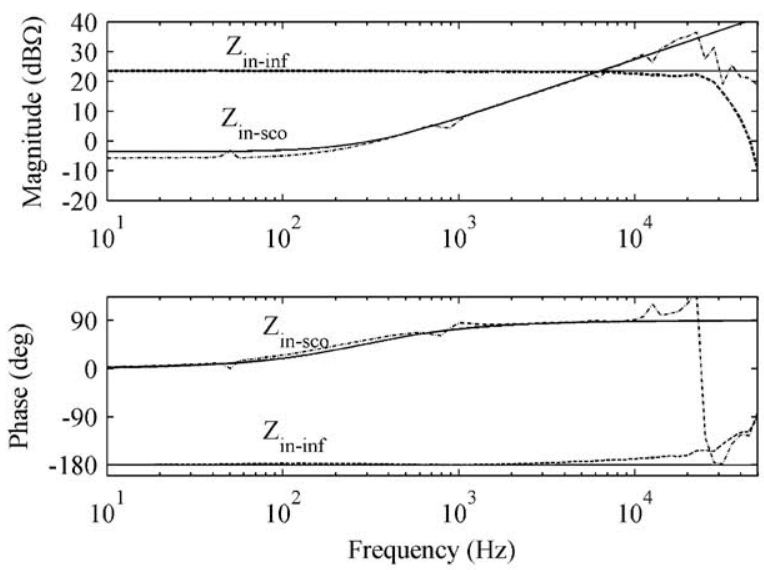

Fig. 13. Measured (dashed lines) and predicted (solid lines) ideal input impedance denoted by $Z_{\text {in-inf }}$ and the short-circuit input impedance denoted by $Z_{\text {in-sco }}$.
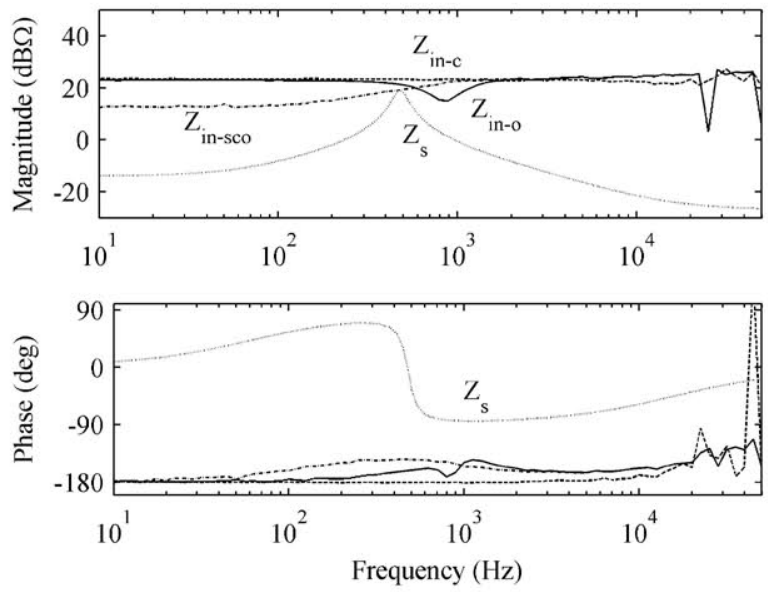

Fig. 14. Measured input impedances of the IVFF-controlled converter with the input-filter output impedance.

means that both of the resonant circuits affect the converter simultaneously. Fig. 12 clearly shows that both of the minorloop gains equally indicate that the converter is stable. The inputside minor-loop gain contains 40 data points/decade and the output side contains only 20 data points/decade. This difference is clearly visible in Fig. 12(b) reducing the accuracy of the Nyquist plot information.

As an example, the measured and predicted ideal input impedance $Z_{\mathrm{in}-\infty}$ and the input impedance at short-circuited output $Z_{\text {in-sco }}$ are presented in Fig. 13. The experimental responses are computed according to (3) and (4) by means of the corresponding measured open-loop frequency responses. The predictions are computed based on the component values of the power stage in Fig. 2 according to (13) and (14). The accuracy of the predictions is quite satisfactory.

\section{B. IVFF-Controlled Converter}

Fig. 14 presents the measured input impedances of the IVFFcontrolled converter illustrating that the input impedances are not equal as they would be if the audiosusceptibility is perfectly nullified. The short-circuit input impedance is slightly reduced
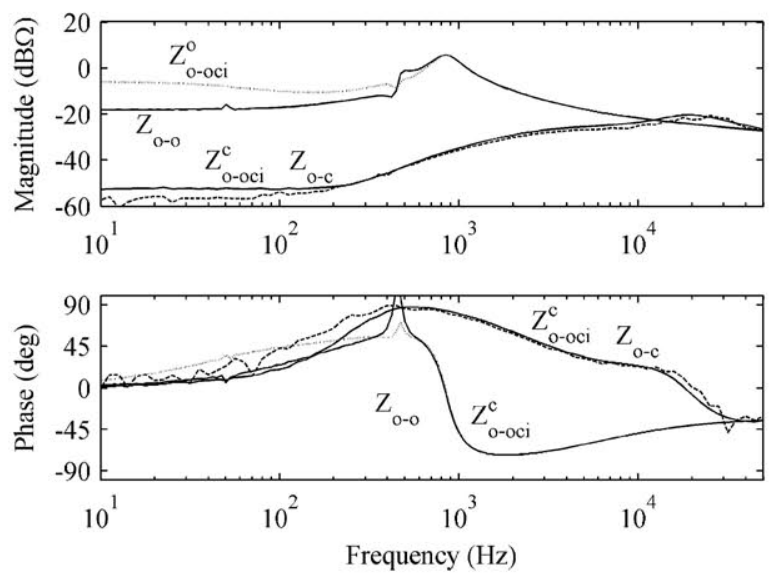

Fig. 15. Measured open- and closed-loop output impedances (solid line) as well as open (dotted line)- and closed-loop (dashed line) open-circuit output impedances.
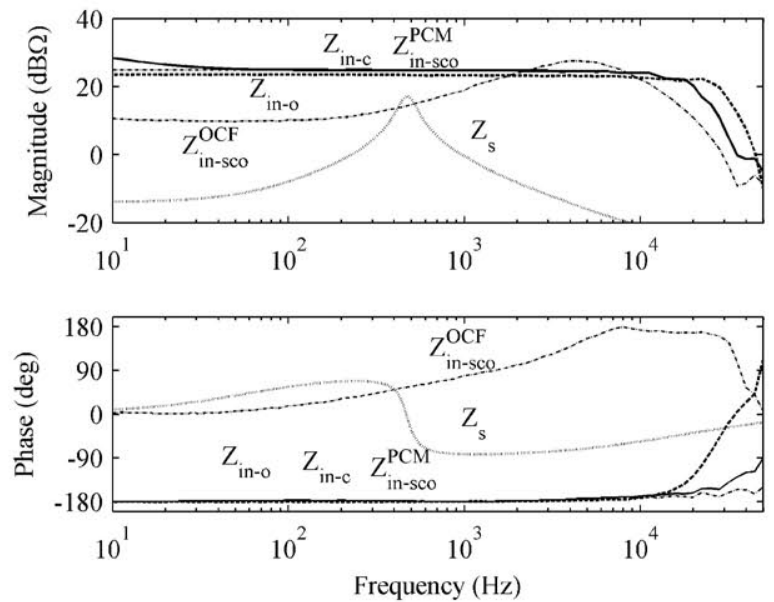

Fig. 16. Measured input impedances of the PCM- and PCM-OCF-controlled converters.

as discussed in Section III but it is, however, significantly larger than the short-circuit input impedance of the DDR-controlled converter (see Fig. 7) implying reduced source interactions as shown explicitly in [21].

Fig. 15 shows the measured output $Z_{\mathrm{o}-\mathrm{x}}$ and open-circuit output $Z_{\mathrm{o}-\mathrm{oci}}^{\mathrm{x}}$ impedances of the IVFF-controlled converter illustrating that both the open- and closed-loop impedances as pairs are quite close to each other, preventing the load impedance to interact with the input impedance as discussed earlier and demonstrated in [17].

\section{PCM-Controlled Converters}

The measured input impedances of the PCM- and PCM-OCFcontrolled converters are presented in Fig. 16 showing that the input impedances of a PCM-controlled converter are essentially the same. This explains the converter invariance to the source impedance interactions as discussed earlier in Section III. The figure illustrates that the short-circuit input impedance of the PCM-OCF-controlled converter is reduced, because the inputnoise attenuation is not perfect (see Fig. 6) and the open-loop 

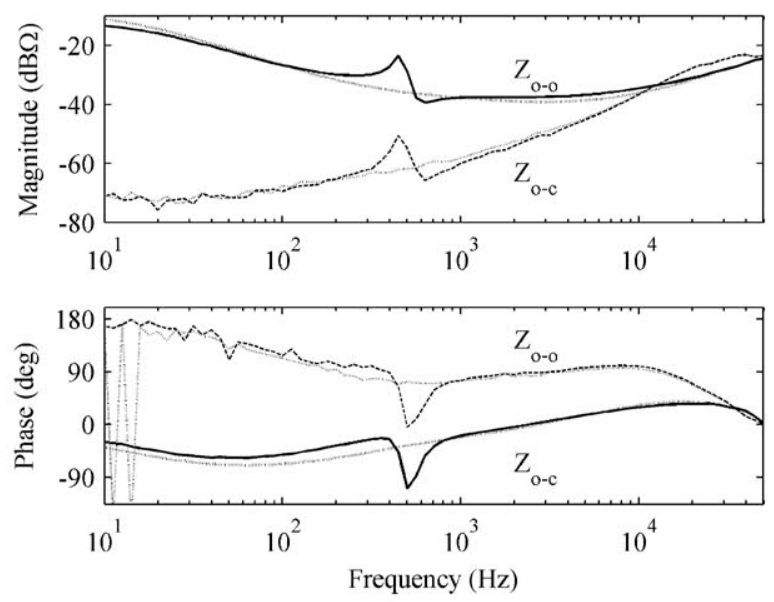

Fig. 17. Measured open- and closed-loop output impedances of the PCMOCF-controlled converter.

output impedance is small (see Fig. 17) as previously discussed in Section III. It can be observed in Fig. 16 that the inputfilter output impedance intersects with the short-circuit input impedance, and therefore, the output impedances would be slightly affected as explicitly shown in Fig. 17. The resonant peaking in the open- and closed-loop output impedances is the same indicating that the peaking in the input-side minor-loop gain has not affected the closed-loop output impedance but the origin of the affection is solely the intersection of the shortcircuit input impedance and the filter output impedance. The resonant behavior at the output impedance is so insignificant that it does not affect the load-transient behavior.

The output-side impedances (i.e., $Z_{0-\mathrm{o}}, Z_{\mathrm{o}-\mathrm{c}}, Z_{\mathrm{o}-\mathrm{oci}}^{\mathrm{o}}$, and $Z_{\mathrm{o}-\mathrm{oci}}^{\mathrm{c}}$ ) would behave as pairs in the same way as shown in Fig. 15 meaning that the load impedance does not affect the input impedance as demonstrated in [30] and discussed earlier in Section III.

\section{CONCLUSION}

The main purpose of this paper is to demonstrate that the control method has a significant impact on the source- and loadimpedance interactions in the converter. A buck converter was chosen as an example, because it is the most common building block in dc-dc distributed systems. The ready-made power modules are very often provided with limited information on their internal components and control methods necessitating the dynamic characterizing to be based on measured frequency responses. Therefore, the study in this paper was based only on the measured frequency responses. The given analytic models were used as media to explain the observed phenomenon in an understandable manner. The validation of the given small-signal models is performed earlier in the named sources.

This paper provided a comprehensive study on the effect of the control method on the impedance-based interactions in a buck converter operating in CCM. The authors of [25] show that even the change in operational mode from continuous to discontinuous mode in a DDR-controlled buck converter reduces the interactions. The observed interaction-sensitivity reduction in a PCM-controlled converter was explained to origin from the fact that all the input-side impedances are the same and the output-side impedances pair-wise the same effectively canceling the interactions. It was also stated that the small output impedance in the IVFF- and PCM-OCF-controlled converters reduces the short-circuit input impedance thus making the converter slightly more sensitive to the source interactions than the PCM-controlled converter. The most interaction sensitive converter is the DDR-controlled converter due to the internal resonant behavior and the low input-noise attenuation. It is obvious that the low-loss design would boost the resonant behavior and thereby increase the interaction sensitivity. It was also explicitly demonstrated that the input- and output-side minor-loop gains equally predict the stability of the converter.

The comprehensive validation of the analytic models was out of scope of this paper but as an example it was demonstrated that the special impedance parameters can be computed based on the measured frequency responses. The comparison to the predicted and measured responses indicated good accuracy between the measurements and predictions. The derivation of the special impedance parameters shows that the correctness of the basic analytic models implies also the correctness of the analytic models of the special parameters, because they are interconnected. It is also worth noting that the special impedance parameters cannot be measured directly but only computed based on the measured frequency responses of which they are composed.

\section{REFERENCES}

[1] N. O. Sokal, "System oscillations from negative input resistance at the input of switching-mode regulator, amplifier, DC/DC converter or DC/AC inverter," in Proc. IEEE Power Electron. Spec. Conf., 1973, pp. 138-140.

[2] N. O. Sokal and D. E. Nelsen, "Preventing input-filter oscillation in switching regulators," in Proc. Powercon, 1975, vol. 2, pp. 293-294.

[3] R. D. Middlebrook, "Input filter considerations in design and applications of switching regulators," in Proc. IEEE Ind. Appl. Soc., 1976, pp. 91-107.

[4] R. D. Middlebrook, "Design techniques for preventing input-filter oscillations in switched-mode regulators," in Proc. Powercon, 1978, vol. 5, pp. A3.1-A3.16.

[5] D. M. Mitchell, "Damped EMI filters for switching regulators," IEEE Trans. Electromagn. Comput., vol. EMC-20, no. 3, pp. 457-459, Aug. 1978.

[6] S. Y. Erich and W. Polivka, "Input filter design criteria for currentprogrammed regulators," IEEE Trans. Power Electron., vol. 7, no. 1, pp. 143-151, Jan. 1992.

[7] C. R. Kohut, "Input filter design criteria for switching regulators using current-mode programming," IEEE Trans. Power Electron., vol. 7, no. 3, pp. 469-479, Jul. 1992.

[8] Y. Jang and R. W. Erickson, "Physical origin of input filter oscillations in current programmed converters," IEEE Trans. Power Electron., vol. 7, no. 4, pp. 725-733, Oct. 1992.

[9] T. Suntio, I. Gadoura, and K. Zenger, "Input filter interactions in peakcurrent-mode controlled buck converter operating in CICM," IEEE Trans. Ind. Electron., vol. 49, no. 1, pp. 76-78, Feb. 2002.

[10] B. Choi, D. Kim, S. Choi, and J. Sun, "Analysis of input filter interactions in switching power converters," IEEE Trans. Power Electron., vol. 22, no. 2, pp. 452-460, Mar. 2007.

[11] P. Li and B. Lehman, "Accurate loop gain prediction for DC-DC converter due to the impact of source/input filter," IEEE Trans. Power Electron., vol. 20 , no. 4 , pp. $754-761$.

[12] M. Cespedes, T. Beechner, L. Xing, and J. Sun, "Stabilization of constantpower loads with passive impedance damping," in Proc. IEEE Appl. Power Electron. Conf., 2010, pp. 2174-2180.

[13] T. Suntio, J. Leppäaho, and M. Hankaniemi, "On EMI-filter interactions in a regulated converter-Stability and load-transient performance," in Proc. IEEE Energy Convers. Congr. Expos., 2009, pp. 3031-3038. 
[14] M. Florez-Lisarraga and A. F. Witulski, "Input filter design for multiplemodule DC power systems," IEEE Trans. Power Electron., vol. 11, no. 3, pp. 472-479, May 1996.

[15] C. M. Wildrick, F. C. Lee, B. H. Cho, and B. Choi, "A method of defining the load impedance specification for a stable distributed power system," IEEE Trans. Power Electron., vol. 10, no. 3, pp. 280-285, May 1995.

[16] M. Hankaniemi, M. Karppanen, and T. Suntio, "Load-imposed instability and performance degradation in a regulated converter," IEE Proc., Electr. Power Appl., vol. 153, no. 6, pp. 781-786, Nov. 2006.

[17] M. Hankaniemi, M. Karppanen, T. Suntio, A. Altowati, and K. Zenger, "Source-reflected load interactions in a regulated converter," in Proc. IEEE IECON, 2006, pp. 2893-2898.

[18] L. Xing, F. Feng, and J. Sun, "Optimal damping of EMI filter input impedance," IEEE Trans. Ind. Appl., vol. 47, no. 3, pp. 1432-1440, May/Jun. 2011.

[19] T. Suntio, M. Hankaniemi, and M. Karppanen, "Analysing the dynamics of regulated converters," IEE Proc., Electr. Power Appl., vol. 153, no. 6, pp. 905-910, Nov. 2006.

[20] M. Karppanen, M. Sippola, and T. Suntio, "Impact of remote sensing on converter stability and performance," in Proc. Eur. Conf. Power Electron. Appl., 2007, pp. 1-10.

[21] M. Karppanen, T. Suntio, and M. Sippola, "Dynamical characterization of input-voltage-feedforward-controlled buck converter," IEEE Trans. Ind. Electron., vol. 54, no. 2, pp. 1005-1013, Apr. 2007.

[22] M. Karppanen, M. Sippola, and T. Suntio, "Multi-channel semi-regulated bus converter," in Proc. IEEE Power Electron. Spec. Conf., 2008, pp. 3259-3265.

[23] R. D. Middlebrook and S. Cuk, "A general unified approach to modeling switching-converter power stages," in Proc. IEEE Power Electron. Spec. Conf., vol. 1976, pp. 18-34.

[24] R. D. Middlebrook, "Null double injection and extra element theorem," IEEE Trans. Educ., vol. 32, no. 3, pp. 167-180, Aug. 1989.

[25] M. Hankaniemi, M. Karppanen, and T. Suntio, "Dynamical characterization of voltage-mode controlled buck converter operating in CCM and DCM," in Proc. 12th Power Electron. Motion Control Conf., 2006, pp. 816-821.

[26] S. D. Sudhoff, S. F. Glover, P. T. Lamm, D. H. Schmucker, and D. E. Delisle, "Admittance space stability analysis of power electronic systems," IEEE Trans. Aerosp. Electron. Syst., vol. 36, no. 3, pp. 965 973, Jul. 2000.

[27] S. Vesti, T. Suntio, J. A. Oliver, R. Prieto, and J. A. Cobos, "Impedancebased stability and transient-performance assessment applying maximum peak criteria," IEEE Trans. Power Electron., vol. 28, no. 5, pp. 2099-2104, May 2013.

[28] L. Nousiainen et al., "Photovoltaic generator as an input source for power electronics converters," IEEE Trans. Power Electron., vol. 28, no. 6, pp. 3028-3038, Jun. 2013.

[29] K. Zenger, A. Altowati, and T. Suntio, "Dynamic properties of interconnected power systems-A system theoretic approach," in Proc. IEEE Conf. Ind. Conf. Ind. Electron. Appl., 2006, pp. 835-840.

[30] M. Karppanen, M. Hankaniemi, T. Suntio, and M. Sippola, "Dynamical characterization of peak-current-mode-controlled buck converter with output-current feedforward," IEEE Trans. Power Electron., vol. 22, no. 2, pp. 444-451, Mar. 2007.

[31] T. Suntio, Dynamic Profile of Switched-Mode Converter: Modeling, Analysis and Control. Weinheim, Germany: Wiley-VCH, 2009.

[32] S. Vesti, J. A. Oliver, R. Prieto, J. A. Cobos, and T. Suntio, "Stability and transient performance assessment in a COTS-module-based distributed DC/DC systems," in Proc. IEEE 33rd Int. Telecommun. Energy Conf., 2011, pp. 1-7.

[33] S. Vesti, J. A. Oliver, J. A. Cobos, R. Prieto, J. Huusari, and T. Suntio, "Practical characterization of input-parallel connected converters with a common input filter," in Proc. IEEE Appl. Power Electron. Conf. , 2012, pp. $1845-1852$.

[34] D. Boroyevich, I. Cvetkovic, D. Dong, R. Burgos, F. Wang, and F. Lee, "Future electronic power distribution systems-A contemplative view," in Proc. 12th Int. Conf. Optimization Electr. Electron. Equipment, 2010, pp. 1369-1380.

[35] C. K. Tse, Linear Circuit Theory. Harlow, U.K.: Addison-Wesley Longman, 1998, pp. 226-240.

[36] T. Suntio, J. Huusari, and J. Leppäaho, "Issues on solar-generatorinterfacing with voltage-fed MPP-tracking converters," Eur. Power Elect. Drives J., vol. 20, no. 3, pp. 40-47, Sep. 2010.

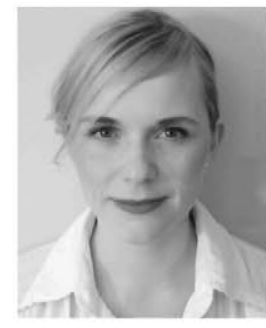

Sanna Vesti (S'10) received the M.Sc. (Tech.) degree in electrical engineering, in 2009, from Tampere University of Technology, Tampere, Finland. She received the second M.Sc. degree in industrial electronics, in 2010, from the Technical University of Madrid, Madrid, Spain, where she is currently working toward the Ph.D. degree in the Centro de Electronica Industrial (CEI).

Her current research interests include dynamic modeling, and design and stability analysis of distributed power systems.

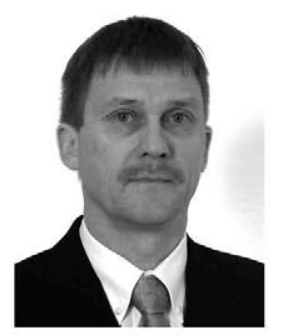

Teuvo Suntio (M'98-SM'08) received the M.Sc. and $\mathrm{Ph} . \mathrm{D}$. degrees in electrical engineering from the Helsinki University of Technology, Espoo, Finland, in 1981 and 1992, respectively.

From 1977 to 1991, he was with Fiskars Power Systems as a Design Engineer and R\&D Manager. From 1991 to 1992, he was with Ascom Energy Systems as an R\&D Manager. From 1992 to 1994, he was an Entrepreneur in power electronics design consultancy, and from 1994 -to 1998 he was with Efore as a Consultant and Project Manager. Since 1998, he has been a Professor specialized in switched-mode power converter technologies first at theElectronics Laboratory, University of Oulu, and in August 2004 he joined the Department of Electrical Engineering, Tampere University of Technology. His current research interests include dynamic modeling and control design of switched-mode power converters in dc-dc systems as well as in renewable energy applications. He holds several international patents. He has authored more than 190 international scientific journal and conference papers the book Dynamic Profile of Switched-Mode Converter-Modeling, Analysis and Control (Wiley-VCH, 2009) as well as two book chapters.

Prof. Suntio is a Member of IEEE Power Electronics, IEEE Industrial Electronics, IEEE Circuits and Systems, and IEEE Power and Energy Societies as well as a member of EPE Association. From the beginning of 2010, he has served as an Associate Editor of the IEEE TRANSACTIONS ON POWER ElECTRONICS. He served also as a quest Editor-in-Chief of the special issue on power electronics in photovoltaic applications of the IEEE TRANSACTIONS ON POWER ELECTRONICS in 2011-2012.

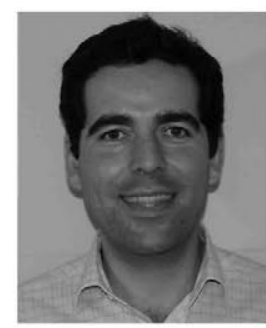

Jesús Á. Oliver (M’00) received the M.S. and Ph.D. degrees in electrical engineering from Universidad Politécnica de Madrid, Madrid, Spain, in 1996 and 2007, respectively.

In 1996, he was a Visiting Scholar at CPES, and in 2000 he held a summer internship at GE R\&D, Schenectady, NY, USA. Since 2001, he has been an Assistant Professor of Electrical Engineering at Universidad Politécnica de Madrid, and in 2007 he became an Associate Professor. He has published more than 120 technical papers and holds three patents. He has been actively involved in more than $60 \mathrm{R} \& \mathrm{D}$ projects for companies in Europe, the U.S., and Australia. His research activities include modeling and control of power electronics converters and systems, high dynamic response power converters for RF applications, and energy-efficient applications. 


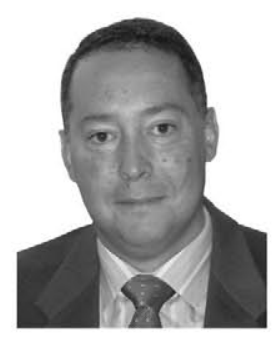

Roberto Prieto (M'99) received the M.S. and Ph.D. degrees in electrical engineering from the Universidad Politécnica de Madrid, Madrid, Spain, in 1993 and 1998 , respectively.

He has been an Associate Professor at the Technical University of Madrid, Madrid, Spain, in the Power Electronics Group (División de Ingeniería Electrónica) since 1998. Since 1999, he has been coordinating the Modeling and Computer Aided Design Division, Power Electronics Research Group. Prior to that, he was an Assistant Professor in the same group for five years (1993). He has published more than 120 papers at international conferences (most of which were sponsored by the IEEE). He is also a coauthor of several international patents and a technical advisor for several IEEE conferences and journals. He has been the advisor on more than 20 master's theses and 5 doctoral theses and has participated in more than 60 research projects. His main research interest includes the design and modeling of magnetic components and power electronics systems.

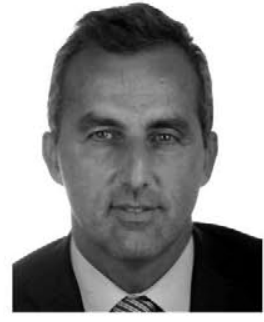

José A. Cobos (M'91) received the Master's and $\mathrm{Ph} . \mathrm{D}$. degrees in electrical engineering from the Technical University of Madrid (UPM), Madrid, Spain, in 1989 and 1994, respectively.

He has been a Professor at UPM since 2001. His contributions are focused in the field of power supply systems for telecom, aerospace, industrial, automotive, and medical applications. He has advised 14 doctoral dissertations, published more than 200 technical papers, and holds 6 patents. He is the Director of the "Centro de Electrónica Industrial, CEI-UPM," a university research center, leading a strong industrial program in power electronics, with technology transfer through more than 50 direct R\&D contracts with companies in Europe, the US, Australia, and China. His research interests include energy efficiency in microprocessors and RF amplifiers, magnetic components, piezoelectric transformers, transcutaneous energy transfer, and dynamic power management.

Dr. Cobos received the "UPM Research and Development Award for faculty less than 35 years of age," and the "Richard Bass Outstanding Young Power Electronics Award of the IEEE" (year 2000). Recently, he received the Semikron Innovation Award for the teamwork on "RF Power Amplifier with Increased Efficiency and Bandwidth." The CEI-UPM was awarded among the top five European universities by the EPSMA in 2007, and awarded with the "UPM Technology transfer award" in 2006. He has been cooperating with the IEEE and other professional associations (reviewer, session chair, topic chair and Associate Editor). Since 2003, he has been serving as an Associate Editor of the IEEE TRANSACTIONS ON POWER ELECTRONICS. From 2002 to 2005, he served as an Associate Editor of the IEEE POWER ELECTRONICS LETTERS. He is an AdCom member of the IEEE Power Electronics Society. 